\title{
Miradas científico anormales a la infancia en situación de calle: José Gutiérrez o los imaginarios sociales modernos*
}

\author{
Revista Colombiana \\ Investigaciones de Educación, N. 63. \\ Segundo semestre de 2012, \\ Bogotá, Colombia.
}

\section{// Some 'scientific and abnormal' focus \\ upon street-children: Jose Gutierrez and modern social imaginary}

\section{//Olhares "científico-anormais" sobre a infancia em situação de rua: josé gutiérrez ou os imaginários sociais modernos}

\section{Ivannsan Zambrano Gutiérrez**}

Recibido:29/06/2012 Evaluado:30/08/2012

\begin{abstract}
* $\quad$ Agradezco a los maestros Jesús Alberto Echeverri y Arnulfo Díaz y a las maestras Mercedes Minnicelli, Mariela Rodríguez, Paula Martínez y Diana Posada por la invaluable lectura, recomendaciones y diálogos en torno a este artículo. El mismo, en una versión preliminar y reducida, con un leve cambio en el título, sirvió de ponencia en el Primer Congreso Internacional de Historia Intelectual de América Latina y se presenta como producto de algunas reflexiones propiciadas en la investigación en curso; "Una infancia bajo amenaza de muerte; los niños en situación de calle en las grandes urbes Colombianas. Aportes a una historia de la infancia", aprobada por el Centro de Investigaciones Educativas y Pedagógicas (Ciep) de la Facultad de Educación de la Universidad de Antioquia. Tesista de la licenciatura en Pedagogia Infantil de la Universidad de Antioquia. Miembro en formación del grupo de Historia de la práctica pedagógica. Correo electrónico: wisdomivannsan@hotmail.com
\end{abstract}

\section{Resumen}

José Fulgencio Gutiérrez (1927-2008) sin duda fue uno de los intelectuales colombianos más importantes en los estudios sobre las actuales infancias en situación de vulnerabilidad, específicamente y en el caso de este pensador, los niños en situación de calle. Su obra suma más de 1.200 páginas. La vastedad de sus análisis multidisciplinares lo hacen uno de los autores constantemente citados cuando se habla de la población en situación de calle en la historia pasada y presente de la nación. Este artículo se pregunta por los imaginarios sociales (Pintos, 2004, Castoriadis, 1975) que de la década de los sesenta a finales de los noventa circularon sobre la infancia en situación de calle en Bogotá. En primer lugar, se presentan algunos elementos biográficos del autor, que especifican sus obras, sobre las cuales se realiza el revelamiento de imaginarios. En segundo lugar, se explicitan brevemente elementos teóricos y metodológicos a través de los cuales se lleva a cabo la observación, estableciendo así cómo se observa y desde dónde se observa al autor y su obra. En tercer y cuarto lugar, se efectúa el análisis teniendo por lente el marco teórico y metodológico que precede, para finalmente presentar las conclusiones.

\section{Abstract}

Undoubtedly Jose Fulgencio Gutierrez (1927-2008) was one of the most important Colombian thinkers of vulnerable childhood issues, specifically children living on the streets. His big work includes more than 1200 pages. Also there is a wide recognition of his multidisciplinary analysis, often-cited about homeless population then and now. This paper inquires about social imaginary (Pinto, 2004, Castoriadis, 1975) from sixties to late nineties on children living on the streets in Bogota. Firstly there are some biographical data of author, specifying thereof works on which survey show imaginary generation. Secondly, slight theoretical and methodological issues through which the observation takes place by setting own scenarios of author and his work. Finally, an analysis carried out and based on a theoretical and methodological framework to offer final conclusions.

\section{Palabras Clave}

José Gutiérrez, imaginarios sociales, modernidad, infancia en situación de calle, gamín.

\section{Keywords}

Jose Gutierrez, social imaginary, modernity, childhood on the streets, street-children.

\section{Palavras chave}

José Gutierrez, imaginários sociais, modernidade, infância em situação de rua, menino de rua. 


\section{Resumo}

José Fulgencio Gutiérrez (1927-2008) foi, sem dúvida, um dos intelectuais colombianos mais importantes nos estudos sobre as atualmente chamadas infâncias em situação de vulnerabilidade, especificamente, e no caso deste pensador, as crianças em situação de rua. Sua obra soma mais de 1200 páginas. A densidade de suas análises multidisciplinares faz dele um dos autores constantemente citados quando se fala da população em situação de rua na história passada e presente da Nação. Este artigo indaga sobre os imaginários sociais (Pintos, 2004; Castoriadis, 1975) que, dos anos sessenta ao final dos noventa, circularam a respeito da infância em situação de rua em Bogotá. Considera-se a obra de José Gutiérrez como uma superfície (entre muitas) sob a qual é possível revelar uma parte daqueles imaginários; pois sua obra permite repensar os imaginários que historicamente promoveram práticas sociais, culturais e políticas em torno da infância em situação de rua, também, do presente ao passado, questiona as atuais práticas sobre esta infância e a continuidade ou não dos imaginários encontrados. São apresentados, em primeiro lugar, alguns elementos biográficos do autor, especificando-se as obras sobre as quais se realiza a revelação de imaginários. Em segundo lugar, explicitam-se levemente os elementos teóricos e metodológicos através dos quais se leva a cabo a observação, estabelecendo-se assim como e desde onde se observa o autor e sua obra. Em terceiro e quarto lugar, efetua-se a análise tendo-se por lente o marco teórico e metodológico que precede e, finalmente, apresentam-se as conclusões.

Pero el individuo solo no existe: existe rodeado por una sociedad, inmerso en una sociedad, sufriendo en una sociedad, luchando o escondiéndose en una sociedad. No ya sus actitudes voluntarias y vigilantes son la consecuencia de ese comercio perpetuo con el mundo que lo rodea: hasta sus sueños y pesadillas están producidos por ese comercio. Los sentimientos de ese caballero, por egoísta y misántropo que sea, ¿qué pueden ser, de donde pueden surgir sino de su situación en ese mundo que vive?

Sábato (2006, p. 15).

José Fulgencio Gutiérrez ${ }^{1}$ es y fue, sin duda, uno de los intelectuales colombianos más importantes en los estudios sobre las actualmente consideradas infancias en situación de vulnerabilidad, en específico y en el

1 Gutiérrez hizo parte de las Juventudes Comunistas, fue un estudiante destacado y crítico en la Universidad Nacional, donde estudió medicina y de donde egresó en 1954, también fue fundador de la revista Bisturí en dicha universidad; espacio de crítica a la orientación fisiologisista de la enseñanza media y oligarca en ella presente. Profesor universitario en la Universidad Nacional Autónoma de México y en la Universidad CWRV Cleveland y del grupo psicoanalítico confrontativo de París, fue miembro de la Sociedad Colombiana de Psiquiatría y de la Academia Americana de Psicoanálisis. Formó parte del Movimiento Revolucionario Liberal (MRL) junto a Alfonso López Michelsen y fue uno de los fundadores del Movimiento Político de la Izquierda Democrática, Firmes, al lado del maestro Gerardo Molina, también fue asesor político de la Unión de Trabajadores Colombianos, UTC, de la Comisión de Paz en el Gobierno de Belisario Betancur, miembro fundador de la Fundación Consiso -institución que trabaja por el futuro y bienestar de los niños y niñas desplazados por el conflicto armado en Colombia- y presidente del Comité Permanente de Defensa de los Derechos Humanos. Fue discípulo de Erich Fromm. Para un mayor conocimiento sobre la vida personal y profesional de este importante intelectual, existe un libro titulado La autobiografía en la literatura colombiana, de Vicente Pérez Silva (1996), donde se encuentra transcrita una agradable entrevista a Gutiérrez. 
caso de este pensador, los niños de la calle en otrora llamados "gamines" o lo que actualmente es nombrado en el mundo académico como niños en situación de calle (en adelante NSC).

La obra de este psicoanalista, psiquiatra, político, médico, biógrafo, escritor y traductor en torno a esta infancia suma más de 1.200 páginas. La vastedad de sus análisis, efecto de trabajos de campo de tipo etnográfico, sociológico, estadístico y psicoanalítico, lo hacen uno de los autores inevitablemente citados cuando se habla de la población en situación de calle en la historia pasada y presente de la nación. Fue uno de los primeros intelectuales en dedicarse profundamente al estudio de los NSC.

A Gutiérrez se le considera como una parte -de suma importanciaen el magma de significaciones sociales de la "sociedad colombiana" (Gutiérrez, 1972) en la segunda mitad del siglo XX. Las investigaciones realizadas, la publicación de artículos y libros sobre esta población, la ayuda brindada para la creación de instituciones en beneficio a esta infancia y la vinculación de la misma a la vida personal del autor permiten considerar a Gutiérrez como uno de los principales y fundamentales autores en el campo de la infancia, y en específico en las actuales infancias en situación de vulnerabilidad, un autor en quien se pueden visibilizar los imaginarios en torno a los NSC y que por su papel destacado en el estudio de estos cobra relevancia. Los imaginarios sociales en torno a esta infancia hacen parte de un centro simbólico o parte de él (Carretero Pasin, 2011) posibilitado en el marco de los imaginarios sociales en Bogotá, en torno a la población en situación de calle; imaginarios que circularon y se agruparon principalmente sobre la segunda mitad del siglo XX, caracterizados por inseguridad, el miedo, el desprecio y rechazo hacia esta población. Y que, con sutiles diferencias, se presentan en las diferentes obras de Gutiérrez, distanciados en el tiempo.

El doctor Gutiérrez reflexionó y promovió un "método psicoanalítico" (Gutiérrez, 1972) para el trabajo con la población infantil en situación de calle, este trabajo se llevó a cabo durante al menos tres años en todos los espacios habitados por el intelectual; es decir, su casa, su oficina, sus lugares de tránsito comunes e incluso los hogares de sus vecinos, sus familiares y amigos más cercanos, el detalle no es menor, se trata de un compromiso alto que trascendió los espacios de trabajo académico y profesional y que desafió las prácticas de atención del psicoanálisis, acostumbrado a los espacios privados, encerrados y según él- al diván.

En Gutiérrez se pueden percibir dos líneas de trabajo que lideró en el transcurso de su vida, una línea psicoanalítica con un marcado acento académico, y otra más social e histórica, las dos en momentos 
cruzadas, pero diferenciadas en las distintas obras; por ejemplo, en la primera línea se destacan obras como Medio siglo de travesía freudiana por Colombia, El método psicoanalítico de Erich Fromm y Silencio y verdad. Negación y estima en el psicoanálisis, entre otras. En la segunda línea, se inscriben las obras que se analizaron y que contienen las investigaciones sobre los NSC, esto es, Infancia en miseria (1967), Gamín: un ser olvidado (1972) y Gamín: mi vida con los niños de la calle (1998), esta última contiene algunos capítulos de un libro titulado Doctor: algunas tendencias de la cultura colombiana, del letrado al gamín y el colono (1990).

Gutiérrez escribe su obra en primera persona, principalmente; Gamín: un ser olvidado, según él, es él mismo. "Único medio como podría subrayar mi personal incorporación al tema" (1972, p. XV). A diferencia de otros autores que construyen una armazón "objetiva" y "científica" caracterizada por formas gramaticales en tercera persona, estableciendo una clara distinción entre lo observado y quien observa, Gutiérrez decide, en beneficio a sí mismo y a la vinculación con la población estudiada, escribir en primera persona. Este aspecto cobra importancia, pues el autor deja correr en tinta sin reserva y cuidado, sus concepciones, sus maneras de pensar, sus objeciones y contradicciones, su vida y la vida de los otros; las opacidades y relevancias son evidentes.

\section{Aspectos metodológicos y de observación}

El relevamiento de los imaginarios sociales ${ }^{2}$ se efectúa a través de una operación de triangulación metodológica en la que, siguiendo a Juan Luis Pintos y Castoriadis, se posibilita sacar a luz los imaginarios sociales, mediante el uso del metacódigo relevancia/opacidad. Tal operación exige el diseño de un mecanismo de observación que visibilice las diferencias, delimitando así lo observable, que es propio del ejercicio investigativo en particular. Una observación de segundo orden sobre una de primer orden -en este caso la ejecutada por Gutiérrez- posibilita el relevamiento de los imaginarios que circulan o circularon

2 Se entiende por imaginarios sociales al entramado de redes simbólicas que permea las interacciones sociales; a la vez que constituye y da vida a los simbólicos de aquella red, el mismo es siempre cambiante. El imaginario social se presenta como un espacio simbólico que contiene un conjunto de significantes, significaciones, prácticas, creencias y discursos que constituyen un "magma de significaciones sociales" (Castoriadis, 1975) que reúnen, cohesionan y visibiliza a un colectivo determinado (un grupo, una institución, una comunidad). 
debido a su posición; la distinción ${ }^{3}$ que establece una posición -observación de segundo orden- frente a la que tiene o tenía el observador de primer orden.

La distinción relevancia/opacidad visibilizada en aquel metacódigo señala un "código" que tiene que ver con una perspectiva fenomenológica de "presencia y ausencia" (Pintos, 2005).

Se opera con tres componentes básicos, inherentes al mecanismo diseñado:

1. La observación que da vida a una diferencia. Esta no invalida la observación de primer orden, pues tanto la observación de primer como de segundo orden tanto lo falso como lo verdadero- están contenidos en el sistema social que en la investigación se enmarca en una realidad, ubicada en un tiempo y espacio determinados.

3 La distinción es un aspecto inherente al observador, todo aquel que observa establece un diferenciante. Observar, siguiendo a Pintos (2005), es: "Como repetimos siempre, generar una diferencia con la ayuda de una distinción, que no deja fuera con ello nada distinguible. En el medio verdad, el sistema comunicativo sociedad constituye el mundo como una totalidad, que incluye todo lo que es observable y hasta el observador mismo. Con ese objetivo se establece en el mundo un sistema observador que se observa a sí mismo, que tiene disponibilidad sobre el valor reflexivo de la falsedad (y tiene disponibilidad también sobre lo observable, lo empírico y lo fáctico, evidentemente) y de ese modo puede marcar algo cuyo correlato no puede ser atribuido al mundo".
2. La construcción de la marca, una distinción, es decir, de la posición. "Una distinción tiene siempre dos partes, consiste propiamente en una frontera que hace posible diferenciar ambas partes y pasar de una a otra". El sentido que tiene la separación de ambas partes y su marcaje por la forma de la distinción es obligar al observador a salir de una parte de lo distinguido (y no de la otra). Se tiene que indicar lo que será observado; hay que "dar una referencia" (Pintos, 2005).

3. El "establecimiento de la unidad inseparable de marca y diferencia". Entendida en la investigación como una posición establecida reflexivamente en torno al marcaje y la observación.

Sobre lo anterior, la mirada -posición de observación- que se asume en esta investigación diferencia entre las miradas y conceptualizaciones que "señalan" y "acusan" a la infancia en situación de calle, en el marco de sus acciones, y los fines bajo los cuales son caracterizados (acciones delictivas), de aquella -a través de la cual se observa, se mira- que explica las razones y los motivos que dan vida a la nombrada infancia comprendiéndola en el marco de su diversidad y necesidad de sobrevivencia (Minnicelli y Zam- 
brano, 2012), en esta línea se ven con sospecha las reflexiones de corte modernizante y capitalista e incluso civilizadas, con las cuales se observa a los NSC, y a través de las cuales se intenta comprenderlas señalándolas con base en su "anormalidad" e "incivilidad".

\section{Los imaginarios; Gutiérrez y los otros, los otros y Gutié- rrez; nosotros y ellos}

Se procede de esta forma a entrar en las letras de José Gutiérrez. Sus palabras, en 1972, nos brindan un escenario de inicio interesante:

Al resurgir de este mundo saturado de miasmas, creo que conozco más a Colombia: sé lo que piensan esos filósofos de la calle, cuyos curtidos rostros a veces llegan a dar la impresión de ser conscientes del crítico papel que juegan en la vida social. Y he creído entender también por qué y para qué la sociedad los bautiza de tan curiosa manera y los lleva presentes en cada uno de sus actos: son los gamines como criaturas diabólicas que viven martirizando el diario ocurrir de la vida pública, de día y de noche (Gutiérrez, 1972, p. XV).

Gutiérrez sintetiza en este enunciado, ubicado en una de las primeras páginas del libro, un acercamiento reflexivo a los actualmente denominados NSC. En el entramado de variables que configuran el enunciado, se visibiliza el papel de la sociedad y los imaginarios sociales que la contienen. Llama la atención la función de aquella sociedad: "bautizar" y no pasa desapercibido a quien bautiza; "criaturas diabólicas". Por su parte, Gutiérrez, asume que los NSC "a veces llegan a dar la impresión de ser conscientes del crítico papel que juegan en la vida social". Son tres variables interesantes ${ }^{4}$, una con un contenido "terapéutico" de corte religioso, dos, la presencia de la "vida pública" alterada por la existencia de "criaturas diabólicas" que "martirizan" y

4 No se profundiza en cada una de las variables, de las instituciones. No se indaga por los discursos ni imaginarios que hicieron posible tal práctica terapéutica -en la historia de la institución- en el caso de la Iglesia, ni en este caso, las razones históricas y simbólicas que hicieron posible la anormalidad de la presencia de los NSC en la vida pública. Nótese que el interés reside en evidenciar los imaginarios a los que Gutiérrez da relevancia, imaginarios que necesariamente pasan y habitaron en diversas instituciones, lo cual demuestra su poderío, imaginarios que son utilizados para explicar el mundo. 
por lo mismo son objeto de la terapéutica religiosa, tres, la asignación de responsabilidad individual a los NSC, que alcanzan a ser "conscientes del crítico papel que juegan en la vida social".

A través de aquellas variables se evidencia un juego de relaciones en tensión entre la Iglesia, el papel de la vida pública y la institución educativa, de la cual Gutiérrez hacía parte en el campo académico. Cabe señalar, que lo expresado -como se podrá apreciar en otros apartados- hace parte de un plano simbólico ciertamente compartido por las instituciones y los habitantes que hacen parte de ellas, un plano en el que los NSC son objeto de un entrelazamiento de discursos y prácticas religiosas, estatales, policíacas y educativas, entre otras, con tintes despreciativos, discriminantes, acusantes, moralizantes, anormalizantes y de desconfianza, habilitadas por unas "condiciones simbólicas de posibilidad" (Baczko, 2005, p. 17) que recaen sobre el niño en situación de calle y lo que este simboliza, con intención -no siempre llevada a la práctica- de modelarlo, corregirlo e integrarlo mediante la normalización a la "sociedad colombiana" (Gutiérrez, 1972). Estos simbólicos representan un bloque de imaginarios "inestables", en movimiento, poco o muy consolidados, pero en todo caso cohesionados. Dichas tensiones están alojadas en un magma de significaciones sociales, del cual Gutiérrez hacía parte.
Gutiérrez, al interior de aquel magma de significaciones, establece una serie de significantes ${ }^{5}$, a través de las cuales caracteriza a los NSC; significantes que encierran en sí mismos aspectos simbólicos que los cohesionan y, por lo mismo, vehiculan un acercamiento al modo en que eran nombrados y significados en la sociedad. Estos significantes, en 1972, se materializaban reiteradamente en lo siguiente: "Endiablados seres", "diabólicos niños", "guerrilleros urbanos en miniatura", y 25 años después, en 1998, sostendrá: "Mordaces niños", "irredentos callejeros". Se debe prestar atención no solo al modo peyorativo de nombrar, sino a lo que está debajo de aquel modo, a lo que subyace al mismo, en este caso son indudables las conexiones simbólicas con la institución religiosa y el estado en el marco de la vida pública, donde, según el autor, los NSC son responsables de su vida; "El gamín bogotano, en cierta forma, elige su suerte cuando se lanza a la calle y al unirse a la gallada" (Gutiérrez, 1998, p. 10).

Este "mundo gamín", según Gutiérrez, se distancia, se diferencia de la "sociedad colombiana", es

\footnotetext{
Se entiende el concepto de significante, siguiendo a Rorty (1996, citado en: Hurtado Herrera, 2004), como "herramientas del lenguaje que nos constituyen y que se expresan a través de nuestra conciencia, nuestra cultura, nuestra forma de vida", considerando a su vez la especificad que anuncia Minnicelli $(2005$, p. 7), esto es, que el significante admite "múltiples significaciones y sentidos que no pueden quedar capturados en ningún significado".
} 
habitado por seres conscientes y dueños de un "espíritu gamín" (Gutiérrez, 1972, pp. 131-154) (connotación esencialista y en esta perspectiva profundamente simbólica), que caracteriza a esta "sociedad incivilizada" y enemiga "de la vida moderna" (Gutiérrez, 1972, p. 306), la vida de la "sociedad colombiana" o "cultura colombiana oficial".

Sobre lo anterior, en las reflexiones de Gutiérrez no solo se adjudica y cree en la conciencia y, por tanto, responsabilidad que sostenían los gamines en torno a la vida pública, a su vez, aquel "papel" en la vida pública está significado como un elemento cultural en el marco de la modernidad y la civilización, que los diferencia de otros "papeles" u otras vidas, es decir, la "vida gamín " o el "mundo gamín ", frente a la "vida social colombiana oficialmente establecida" (Gutiérrez, 1972, p. 221), "vida social civilizada" (Gutiérrez, 1972, p. 11), o la "vida familiar" contenidas en la "sociedad colombiana", en la "cultura colombiana oficial": La diferencia entre la vida gamín y "la otra" (la vida familiar, tal vez podríamos decir), aparecía muy clara a las horas de comer o descansar en familia, con la presencia de Álvaro y Juan (NSC que Gutiérrez alojó en su casa. (Gutiérrez, 1972, p. 254).

Y continúa. "Porque la sociedad gamín es precisamente eso: una contracultura con símbolos y rituales lo suficientemente fuertes como para oponerse a los de la cultura colombiana oficial, pero no tanto como para darle a este grupo una significación social positiva" (Gutiérrez, 1972, pp. 288-289).

Gutiérrez, al nombrar, al escribir la distinción "vida gamín", "mundo gamín", en oposición a la "sociedad colombiana" o la "cultura colombiana oficial", no hace visible solamente una diferenciación -que por lo mismo habilita reflexiones en torno a la otredad--, sino que materializa semánticamente un contenido simbólico que subyace y tiene vida en aquellos adjetivos, configurando y visibilizando un conjunto de prácticas, creencias y concepciones entre estos significantes, insertos en el mundo social, cultural y económico de Bogotá en la segunda mitad del siglo XX.

Los simbólicos a través de los cuales explica y comprende el mundo Gutiérrez nos permiten una mirada panorámica al pasado de la población analizada, y por lo mismo, al modo de ver y pensar esta población por parte de José Gutiérrez. Los modos de nombrar no operan como adjetivos inertes, sino que están car- 
gados de simbólicos que los estructuran y relacionan en el magma, "El vocabulario no es jamás una herramienta neutra. Por así decirlo, proyecta su sombra sobre el pasado al que se le aplica" (Baczko, 2005, p. 17), estos simbólicos habilitaron que Gutiérrez ciertamente "describiera" a la población en situación de calle, a los niños, pero también que los señalara e identificara por su diferencia, su anormalidad, por habitar en la "vereda de enfrente" (Minnicelli y Zambrano, 2012), de esta forma, sostiene que la vida de ellos es una "desgracia", la "desgracia colectiva del gaminismo" (Gutiérrez, 1972, p. 132) para ellos mismos y para la "sociedad colombiana".

Por otra parte, en los relatos y situaciones que se visibilizan en los libros, específicamente Gamín: un ser olvidado (1972), se aprecian los imaginarios sobre los NSC que otros sujetos sostenían. Sujetos representantes de distintas instituciones (Iglesia, policía, familia), específicamente un sacerdote, un policía, un vecino, un profesor y un familiar de una persona en situación de calle.

Gutiérrez, explicando las razones que lo llevaron a alojar a Álvaro (un niño en situación de calle por aquellas épocas) en su casa, describe -reflexionando sobre las instituciones solidarias con los NSC- lo que ocurría en las instituciones (albergues) para esta infancia:

Las palabras del cura propietario del albergue -dichas en la cadencia de quien repite esta escena diariamente- quedarían grabadas en mi mente $y$ fueron lo definitivo para decidir nuestra vida con Álvaro.

-No se preocupe mi chinito (mi muchachito). Usted se confiesa esta noche de todos sus pecados conmigo y yo lo dejo quedarse en un sitio en donde no le hagan nada esos grandulones. Pobrecito el chinito (esta vez el "muchachito" era un adarme más despreciativo"). ¡Ni parece que sea un gamín, sino que es rubio como la gente decente! (Gutiérrez, 1972, p. 44).

En otro apartado, Gutiérrez describe un problema con la institución policíaca. Se debe resaltar la respuesta del policía (el funcionario) cuando se interpela por haber golpeado a Álvaro.

"-Doctor, doctor -me explicaba minutos más tarde el funcionario sin que yo quisiera aceptarle su conversación-, le pegué porque no sabía que era hijo suyo. Me estaba insultando como si fuera un gamín y... (Gutiérrez, 1972, p. 68).

En otra situación similar, un vecino de Gutiérrez insultaba a un niño en situación de calle acusándolo de un robo. Gutiérrez interviene, y hala al vecino para que acuse al niño frente a un juez. $Y$ el vecino responde:

"-Pero si yo no he acusado a ningún niño. ¡Si es un gamín!" (ibíd.).

Continuando, en una escuela donde Gutiérrez matriculó a Álva- 
ro, se presenta un problema entre Alberto (hijo de Gutiérrez) y Álvaro, problema resuelto por el profesor, que, enterado de la "procedencia pobre" de Álvaro, comenta en ausencia de este a los compañeros:

-El agradecimiento es una virtud que solo las almas nobles pueden alcanzar. Observen ustedes la maldad de este niño más fuerte (Álvaro) que el otro y a quien a pesar de gozar de la generosidad de los padres de Alberto... (Gutiérrez, 1972, p. 132).

Finalmente, en otros apartados, Gutiérrez escribe sobre las cuatro generaciones que hacen parte de la vida de un gamín, Javier. Al respecto, comenta la abuela de este personaje:

Por eso, aunque el matrimonio de Javier fue desde el comienzo un error porque Trinidad es negra, estuve entonces a favor de ella. Y sigo creyendo que si algunos de los muchachos de Javier son gamines, eso se debe, en parte sí, al cruce de razas: pero principalmente, a la irresponsabilidad del padre (Gutiérrez, 1972, p. 175).

La apreciación del cura, de corte eurocéntrico y racista, cercana al modo de compresión de la abuela de Javier, la justificación del policía y el vecino, diferenciando y especificando lo que se entiende por niño y por gamín, dotando a este ultimo de la ausencia del primero en cuanto concepto y realidad (un niño no es un gamín, un gamín no es un niño. A un niño no se le trata como a un gamín, a un gamín no se le trata como a un niño) $y$, finalmente, el señalamiento por parte del profesor a Álvaro, a quien por su procedencia "pobre", se le considera poseedor de un alma "innoble" y con imposibilidad de alcanzar aquella virtud de nobleza por su misma condición, constituye una red de significantes sobre los cuales y en los cuales obra cada una de las instituciones, por ejemplo, la Iglesia, representada por aquel cura que solicita la confesión para redimir el pecado de ser gamín y no ser "rubio como la gente decente", por otro lado, la institución policíaca, que en manos de aquel agente diferencia entre niño y gamín y por lo mismo opera punitivamente contra este último.

Aquella red de significantes se despliega sobre un piso cultural y social entrelazado, cohesionado, un piso en el que existe un cierto consenso alrededor de lo que es ser gamín y los modos 
en que se puede o no relacionarse con ellos, con la "sociedad gamín". Efectivamente, la "cultural oficial colombiana", la "sociedad colombiana" establece una clara distinción entre lo normal; ella misma, y lo anormal; la "sociedad gamín".

Esta es la sociedad ${ }^{6}$-conteniendo, teóricamente, a todos los habitantes de Bogotá por aquellos años- que habitaron las personas en situación de calle, por lo mismo es en esta sociedad donde se gestan estos modos de interacción y significación, modos que la sociedad produce, en la que se produce, ella, siguiendo a Castoriadis (1997), es autocreación.

La red de significados, de esta forma, no tiene por centro de emergencia y producción a Gutiérrez, sino, con sutiles y diversas mutaciones e inestabilidades -como es propio del magma-, a otras personas e instituciones -y a él mismo-, cuyo punto de encuentro es precisamente aquel "desprecio", "rechazo" y señalamiento a los gamines en el marco de la modernidad.

\section{Gutiérrez en sí mismo}

El imaginario social hace parte del universo de simbólicos que constituyen la sociedad. La creación de imágenes, significados, figuras $y$,

6 Una sociedad, cuyos elementos (sujetos, acciones y discursos) son efecto de sí misma; la sociedad crea lo que ve, lo que pasa, lo que piensa. Es la sociedad la que da vida a sus propios imaginarios y desde ellos a sus dimensiones de funcionalidad. en esta línea, la gestación de prácticas, de acciones y elaboración de saberes es producto de aquellos simbólicos creados por y en el imaginario.

Los saberes, esto es, el modo de pensar y racionalizar un objeto con cierta regularidad y temporalidad, no están exentos de aquellos imaginarios. Al imaginario no se le percibe, se estaría de acuerdo con Taylor (2006) en que opera como un mapa mental, que se sigue sin saber que se utiliza.

En Gutiérrez, tal como se viniera a sostener en los debates en torno a la subjetividad (Zemelman y León, 1997) en el campo de las ciencias sociales, tanto la realidad "lo que está fuera del sujeto", como el sujeto "adentro de la realidad" se entremezclan, y ya no es posible sostener, por lo menos, en el campo de las ciencias sociales, que dicha objetividad sea satisfecha. Gutiérrez partía de aquella necesidad de "objetividad", y en esa medida estableció y resignificó el método psicoanalítico en lo que refiere al trabajo con esta población.

Sin embargo, aquel método exigió de su presencia no solo como observador y analizador, sino como objeto de aquello a lo que observaba y analizaba. De esta forma, comenta hacia 1998: "Mi vida se gaminizó por un largo periodo" (Gutiérrez, 1998, p. 24), y es que efectivamente, 25 años antes, por la época de los 60, escribiría que, en su relación con los gamines, ellos se 
volvieron "mis psicoanalistas" (Gutiérrez, 1972, p. 255). En esta perspectiva, las pretensiones de cientificidad se rarifican y la clásica distinción sujeto/objeto se diluye.

Las disputas y tensiones entre metodologías y saberes (sociológicos, psiquiátricos, psicoanalíticos) iban más allá del simple debate académico, estas contenían a Gutiérrez en su totalidad y, por lo mismo, tal como sucede en el terreno de los imaginarios, posibilitaban debates internos, en los que Gutiérrez es defensor y acusante, víctima y victimario, testigo, culpable y, en ocasiones, reproductor de aquellos imaginarios.

A continuación, un poco de aquellos debates:

Yo no le temía al contagio de las costumbres gamines, ni siquiera cuando se trataba de la marihuana, que estaba respaldada con el atractivo de la moda. En todos estos casos veía a mis hijos como más plenamente identificados con mi horizonte vital que con el de los gamines (Gutiérrez, 1972, p. 136).

Tal como se fueron hilvanando los hechos de mi vida con Álvaro y Juan, mi comportamiento con ellos exteriormente no fue muy diferente del de muchos padres de gamines con sus hijos, en cuanto se refiere a la intensidad con que viví sus diabluras, sufrí sus testarudeces y reaccioné ante ellas (p. 119).

El caso es que la manera de ser de los gamines chocaba con cualquier rutina de las que en su conjunto constituyen la vida civilizada, así sea una rutina revolucionaria (p. 156).

La existencia de este grupo de niños errantes, insumisos y acostumbrados a la protesta, me altera y me llena de desasosiego, a veces lindante con la desesperación (1998, p. 7),

En Gutiérrez se visibilizan modos de nombrar, pensar y relacionarse con la población en situación de calle de aquella época que, tal como lo sostiene él mismo, "no fue muy diferente del de muchos padres de gamines con sus hijos". La inestabilidad del imaginario, su mutación y, por lo mismo, su característica simbólica emanan en el magma del cual hace parte el autor, un magma que pervive al interior y exterior de él. De esta forma, 
la fricción entre relevancia y opacidad tiene existencia en el mundo exterior al sujeto y en el interior de este. El magma instituye imaginarios en el sujeto y el sujeto, como habitante del magma, los visibiliza, en ocasiones rarificándolos e inestabilizándolos, incluso modificándolos o reproduciéndolos.

El miedo o no al "contagio" entraña imaginarios -ciertamente compartidos o no por el autor-que Gutiérrez no podía pasar por alto a pesar de la "intención científica" de su investigación. Estos, como es evidente, operaban como lentes a través de los cuales el autor pensaba e interactuaba con el mundo. Para Gutiérrez, existía un "horizonte vital", sin posibilidad de contagio, cuya fuerza libraba a sus hijos y a él de aquel "mundo gamín", por supuesto negativo, peligroso, contagioso y en suma anormal. Considerando a la población en situación de calle como algo -en todo caso- "contagioso", Gutiérrez establece una barrera deficitaria científicamente, en la que su posición de observador se entremezcla con sus imaginarios, posibilitando así un miedo personal y una relación poco diferente a la de los "padres de gamines con sus hijos", con los NSC.

Los imaginarios en Gutiérrez sostienen permanencia, con seguridad un poco modificada con el paso de los años, pero en todo caso existente.

\section{Conclusiones}

En una sociedad como la colombiana, de rápida modernización, en que el individuo debería entrar a participar del objetivo final de la sociedad, el vacío "antisocial" o "marginado" que dejan los grupos que se van creando por razón de la tendencia al asociacionismo propia de la vida moderna puede llegar a abarcar la inmensa mayoría de la nación. Tal es el dramático resultado del subdesarrollo que agobia a las dos terceras partes del mundo actual. Los gamines no son solo unos típicos y caricaturescos representantes de ese género de vida situado fuera de la vida social, tan general en Colombia y en Latinoamérica en el presente, sino una muestra de lo que puede ocurrir a millones en el futuro (Gutiérrez, 1972, p. 261).

En el magma de significaciones sociales que se puede visibilizar en la obra de Gutiérrez, la población en situación de calle es significada a través de la dupla moderno y no moderno, civilizado y no civilizado 
y, finalmente, gamín y no gamín. Esta operación binaria visibiliza el modo en que los imaginarios operan, esto es, mediante series de oposiciones (Baczko, 2005), en este caso, "sociedad colombiana"|"sociedad gamín", entre otras.

Sobre lo anterior, los imaginarios en torno a la población en situación de calle coexisten en constante tensión a través de las letras y reflexiones de Gutiérrez; las tensiones son visibles tanto en lo personal del autor como en el terreno de lo social que describe el mismo. Las relevancias no sumergen las opacidades, al contrario, debido a la escritura en primer persona de Gutiérrez son bastante claras, si bien la intencionalidad del autor es adecuada, "tratamos de acercar los dos mundos opuestos, gamines-sociedad colombiana y de limar asperezas entre uno y otro" (Gutiérrez, 1972, p. 251), llenar de contenido lo que posteriormente denominara un "vacío" $(1972$, p. 256) en dicha operación, sin que, con seguridad se quiera, -el observador de primer orden no es consciente de sus imaginarios- se movilizan aquellos imaginarios.

Los actuales NSC se visibilizan en la obra de Gutiérrez -teniendo por espacialidad a Bogotá en la segunda mitad del siglo XX- debido a su anormalidad, su diferencia, su vida contraria a la modernidad -con todas sus prácticas, creencias y concepciones- en marcha. La "sociedad colombiana" distingue lo diferente a ella; el "mundo gamín", de esta forma -como es propio de la modernidad-clasifica, ordena, culpabiliza y patologiza a esta población por su diferencia, su anormalidad. Aquel "mundo gamín " es objeto de la moral, de los saberes académicos y comunes, de la institución policíaca, familiar y política, de las prácticas colectivas e individuales, los estereotipos, las imágenes, los ideales, entre otros, liderados por la "sociedad colombiana" o "cultura colombiana oficial", de la cual Gutiérrez hacía parte, en todos ellos, los imaginarios en torno a esta infancia sostienen tintes moralizantes, normalizadores, despreciativos, excluyentes e inscritos en el ideal del deber ser. Constantemente señalando que no se puede ser gamín. Se estaría de acuerdo con Baeza, (citado en Dittus, 2011, p. 68) cuando señala que "tal tratamiento de discriminación e interiorización obedece a la existencia de un imaginario radical que genera estigmas y estereotipos negativos que marcan la imagen y la condición de algunos grupos, diferenciados valóricamente de otros estereotipos fabricados en connotación positiva". 
Por otro lado, la "rápida modernización" de Colombia es en realidad un proceso social, económico, cultural y político en contra de aquellos que no pueden inscribirse en el mismo. El asociacionismo, como característica de la modernidad según Gutiérrez, es identificado negativamente por darse en la "sociedad gamín" y no en la "colombiana" -en camino de modernización- y por ser liderado, paradójicamente, por niños:

Si no fuera por lo grotesco que hay en que los gamínes fueran, precisamente niños desamparados, podría decirse que su asociación es un buen ejemplo de la imperiosa necesidad de asociaciones modernas, en una sociedad como la colombiana que avanza hacia la urbanización y el modernismo. (...) Se puede decir que la sociedad gamín jugaba el papel que clubes, agremiaciones y multitud de asociaciones segundarías desempeñan en las sociedades modernas. Tales grupos, de materia muy ágil y poco comprometedora, ofrecen al individuo un marco vital diferente al de la lejanía del Estado y al de la cordialidad absorbente de la familia (Gutiérrez, 1972, p. 328).
La posibilidad de que los niños en su afán de sobrevivir se agremien es mirada con asombro y extrañeza, tal agremiación se considera "secundaria" y ciertamente "de materia muy ágil y poco comprometedora"; Gutiérrez hace visible de esta forma un posicionamiento del cual no logra escapar debido a los imaginarios que lo contienen, y aunque reconoce tal agremiación como de carácter moderno, no la legítima y la observa con sospecha. La institución gamín (Minnicelli y Zambrano, 2012) tiene vida en sí misma, pero una vida "incomoda" para la "sociedad colombiana" y la "cultura colombiana oficial", por tanto es una institución rechazada y deslegitimada por aquella sociedad, y por Gutiérrez.

\section{Referencias}

Baczko, B. (2005). Los imaginarios sociales. Memorias y esperanzas colectivas.Buenos Aires: Nueva Visión.

Bustelo, E. (2005). Infancia en indefensión. Salud Colectiva, 1(3), pp. 253-284.

Carretero Pasin, E. (2011). Imaginario e identidades sociales. Los escenarios de actuación del "imaginario social" como configurador de vínculo comunitario. En Coca, Valero Matas et ál. (Coord.). Nuevas posibilidades de los imaginarios sociales.. España: Colección Tremn-Ceasga. Castoriadis, C. (1975). La institución imaginaria de la Sociedad. Buenos Aires: Tusquets Editores. 
Castoriadis, C. (1986). El campo de lo social histórico. Recuperado de http://www.hemerodigital.unam.mx/ANUIES/itam/estudio/ estudio04/sec_3.html

Gutiérrez, J. (1961). El método psicoanalítico de ErichFromm. Bogotá: Tercer Mundo.

Gutiérrez, J. (1967). La infancia en miseria. Colombia: Biblioteca de Bolsillo.

Gutiérrez, J. (1972). Gamín: un ser olvidado. México: McGraw-Hill.

Gutiérrez, J. (1998). Gamín: mi vida con los niños de la calle. Bogotá: Spiridon.

Gutiérrez, J. (1987). Silencio y verdad. Negación y estima en el psicoanálisis. Bogotá: Instituto Caro y Cuervo.

Gutiérrez, J. (1990). Doctor: algunas tendencias de la cultura colombiana, del letrado al gamín y el colono. Bogotá: Spiridon.

Gutiérrez, J. (1996). Medio siglo de travesía freudiana por Colombia: contrapunto y secuencia de un analista con un antropólogo sobre la vida y obra de este. Bogotá: Spiridon.

Hurtado Herrera, D. (2004). Reflexiones sobre la teoría de imaginarios: una posibilidad de comprensión desde lo instituido y la imaginación radical. Cinta de Moebio. Recuperado de http://redalyc. uaemex.mx/redalyc/src/inicio/ArtPdfRed.jsp?iCve=10102102>

Minnicelli, M. (2005). Función docente en tiempo de los derechos del niño. Infancias y problemas en un mundo que cambia. La familia, los nuevos conceptos, la función docente y la tarea en el aula. Buenos Aires: Ediciones Novedades Educativas.

Minnicelli, M. \& Zambrano, I. (2012). Estudio preliminar sobre algunas instituciones de infancia en tiempos de capitalismo y modernidad: los niños en situación de calle, Colombia. Infeies$R M, 1(1)$. Recuperado de http://www.infeies.com.ar/bajar/Investig_Gamines.pdf

Pintos, J. (2005). Comunicación, construcción de la realidad e imaginarios sociales. Utopía y Praxis Latinoamericana, (10)29.

Taylor, C. (2006). Imaginarios sociales modernos. Barcelona: Paidós.

Sábato, E. (2006). El escritor y sus fantasmas. Seix Barral: Buenos Aires.

Silva Pérez, V. (1996). La autobiografía en la literatura colombiana. Bogotá: Imprenta Nacional de Colombia.

Zemelman, H. \& León, E. (1997). Subjetividad: umbrales del pensamiento social. Anthropos: Barcelona. 